\title{
Corological Contributions for Some Endemic and Rare Taxa from Turkey
}

\author{
Ergin HAMZAOĞLU1*, Murat KOÇ², Turhan ÇETIN³
}

\author{
${ }^{1}$ Department of Elementary Education, Gazi Faculty of Education, Gazi University, 06500, Ankara, Turkey \\ ${ }^{2}$ Department of Traditional, Complementary and Integrative Medicine, Graduate School of Public Health, Ankara Yıldırım Beyazıt University, Esenboğa \\ Central Complex, 06760 Çubuk, Ankara, Turkey \\ ${ }^{3}$ Department of Turkish and Social Sciences Education, Gazi Faculty of Education, Gazi University, 06500, Ankara, Turkey
}

\begin{abstract}
Received: 20.07 .2018
Accepted: 18.09 .2018

Published online: 28.09 .2018

Issue published: 28.12 .2018

Abstract: Narrow endemic and rare plants are the most interesting species of a country's flora. Accordingly, each new population discovered makes important contributions to the taxonomy, morphology, corology, and conservation biology of these species. In this study, new population information of 14 narrow and/or rare taxa from Turkey belonging to Asteraceae (Achillea formosa (Boiss.) Sch.Bip. subsp. amanica (Rech.f.) Ehrend. \& Y.P.Guo, Cirsium sivasicum Yıldı, Arabacı \& Dirmenci, Doronicum macrophyllum Fisch. ex Fisch. subsp. sparsipilosum (J.R.Edm.) Alv.Fern., Galatella linosyris (L.) Rchb.f. subsp. linosyris), Caryophyllaceae (Dianthus macroflorus Hamzaoğlu, Gypsophila festucifolia Hub.-Mor.), Ranunculaceae (Delphinium cinereum Boiss., Ranunculus flammula L. var. ovalis (J.M.Bigelow) L.D.Benson), Boraginaceae (Onosma nigricaulis Riedl), Brassicaceae (Sisymbrium malatyanum Mutlu \& Karakuş), Cistaceae (Tuberaria guttata (L.) Fourr.), Convolvulaceae (Convolvulus oleifolius Desr. var. deserti Pamp.), Caprifoliaceae (Cephalaria aytachii Göktürk \& Sümbül) and Fabaceae (Astragalus polemoniacus Bunge) families have been provided. In addition, new IUCN threat categories are proposed and morphological and taxonomic contributions are made for some of these taxa.
\end{abstract}

Keywords: Endemic, rare taxon, corology, new populations, Turkey.

\section{Türkiye'den Bazı Endemik ve Nadir Taksonlar İçin Korolojik Katkılar}

Öz: Dar endemik ve nadir bitkiler bir ülke florası için en ilgi çekici türlerdir. Tespit edilen her yeni popülasyon bu türlerin taksonomisi, morfolojisi, korolojisi ve nihayet koruma biyolojisi için katkı sağlamaktadır. Burada Asteraceae familyasına ait Achillea formosa (Boiss.) Sch.Bip. subsp. amanica (Rech.f.) Ehrend. \& Y.P.Guo, Cirsium sivasicum Yıldı, Arabac1 \& Dirmenci, Doronicum macrophyllum Fisch. ex Fisch. subsp. sparsipilosum (J.R.Edm.) Alv.Fern., Galatella linosyris (L.) Rchb.f. subsp. linosyris), Caryophyllaceae familyasına ait Dianthus macroflorus Hamzaoğlu, Gypsophila festucifolia Hub.-Mor., Ranunculaceae familyasına ait Delphinium cinereum Boiss., Ranunculus flammula L. var. ovalis (J.M.Bigelow) L.D.Benson, Boraginaceae familyasina ait Onosma nigricaulis Riedl, Brassicaceae familyasına ait Sisymbrium malatyanum Mutlu \& Karakuş, Cistaceae familyasına ait Tuberaria guttata (L.) Fourr., Convolvulaceae familyasına ait Convolvulus oleifolius Desr. var. deserti Pamp., Caprifoliaceae familyasına ait Cephalaria aytachii Göktürk \& Sümbül ve Fabaceae familyasına ait Astragalus polemoniacus Bunge olmak üzere toplam 14 dar endemik ve/veya nadir takson için Türkiye'den yeni yayılış bilgileri verilmiştir. Ayrıca bu taksonlardan bazıları için yeni IUCN tehdit kategorisi önerilmiş, morfolojik ve taksonomik katkılar yapılmıştır.

Anahtar kelimeler: Endemik, nadir takson, koroloji, yeni popülasyonlar, Türkiye.

\section{Giriş}

IUCN ölçütlerine göre; doğada yaşamını devam ettiren ve hakkında yeterince bilgi bulunan bitki türleri Kritik (CR, Critically Endangered), Tehlikede (EN, Endangered), Duyarlı (VU, Vulnerable), Tehdite Yakın (NT, Near Threatened) veya Düşük Riskli (LC, Least Concern) olarak tanımlanan tehdit kategorilerinde yer alırlar. Bunlardan CR, EN ve VU koruma gerektiren kategorilerdir. Bir türün, bu kategorilerin hangisinde yer aldığına karar verilebilmesi için yayılış alanı genişliğinin ve birey sayısının bilinmesi oldukça önemlidir (IUCN, 2001). Dolayisiyla, koruma gerektiren tehdit kategorilerinin herhangi birinde yer alan bir bitki türü için yeni popülasyon bulmak, türün bilinen tehdit kategorisini doğrudan etkileyen önemli bir bulgudur. IUCN'e göre soyu tehdit altında olan türler, $\mathrm{A}^{\prime}$ dan E'ye kadar sıralanmış 5 ölçüt bakımından değerlendirilir. Yeni popülasyon keşfi, bu ölçütlerden özellikle A ve B'yi doğrudan etkilemektedir. A ölçütü "populasyondaki azalma", B ölçütü ise "yayılış alan genişliği" ile ilgilidir (IUCN, 2001). Her yeni popülasyon keşfi, türün popülasyon sayısını artırır ve yayılış alanını genişletir. Dolayısıyla bu bulgular, bir türün mevcut tehdit kategorisinin sabit kalmasına veya daha alt düzeye çekilmesine katkı sağlar.

\section{Materyal ve Metot}

Burada yeni popülasyonları verilen endemik ve/veya nadir taksonlar, Türkiye'nin değişik illerinde farklı zamanlarda yapılan taksonomik çalışmalar esnasında toplanmıştır. Taksonlara ait yayılış bilgilerinin yazılımında olabildiğince detaylı adresle birlikte GPS kaydı da verilmiştir. Yeni popülasyon kaydı verilen taksonlara ait diagnostik karakterleri gösteren resimler verilmiştir. Toplanan örneklerin muhafazasında, ilgilenen araştırıcıların kolaylıkla ulaşabilmesi için ANK, EGE, GAZI, HUB, ISTE, ISTO, KNYA ve VANF gibi çok sayıda örnek içeren herbaryumlar tercih edilmiştir. Tehdit kategorilerinin önerilmesinde yayılış alan genişliği dikkate alınmıştır. Ancak tercih edilen habitatın özelliği ve olası antropojen etkiler de değerlendirmeye dâhil edilmiştir (IUCN, 2001).

\section{Bulgular}

\subsection{Asteraceae}


3.1.1. Achillea formosa (Boiss.) Sch.Bip. subsp. amanica (Rech.f.) Ehrend. \& Y.P.Guo

(Syn. Leucocyclus formosus Boiss. subsp. amanicus (Rech.f.) Hub.-Mor. \& Grierson)

C4 Mersin: Aydıncık, Yenikaş-Karadağ köyleri arası, orman yolu, 36 $06^{\circ} 34^{\prime \prime} \mathrm{K}-33^{\circ} 15^{\prime} 14^{\prime \prime} \mathrm{D}, 485 \mathrm{~m}$, orman açıklığı, kalker kayalıklar, 3.6.2014, Hamzaoğlu 7012 (ANK, GAZI, ISTE, KNYA).

Türkiye Florası'nda verilen alttür teşhis anahtarına göre involukrum ve ligula ölçüleri dikkate alındığında toplanan örneklerin subsp. amanica' ya ait olduğuna karar verilmiştir (Şekil 1). Mevcut verilere göre bu alttür Adana, Osmaniye, Hatay ve Şanlıurfa'da, 1050-2000 metreler arasında, açıkta veya orman içindeki kalker kayalık ve akışkan taşlıklarda yetişmektedir (Grierson, 1975a; Küçükbay et al., 2011). Yeni popülasyon verisinin eklenmesiyle birlikte, taksonun tercih ettiği alt yükselti aralığı 485 metreye düşümü, yayılışının batıya doğru devam ettiği anlaşılmış ve yayılış alan genişliği yaklaşık $40.000 \mathrm{~km}^{2}$ olmuştur (Şekil 2). Son bulgular IUCN ölçütlerine göre değerlendirildiğinde, yayılış alanının genişliği nedeniyle takson için LC kategorisi önerilmektedir (IUCN, 2001).

\subsubsection{Cirsium sivasicum Y1ld1z, Arabac1 \& Dirmenci}

B7 Sivas: İmranlı, Darıseki köyü yol ayrımı, 39²0'26"K38¹9'22"D, $1270 \mathrm{~m}$, aşınmış yamaçlar, 11.7.2009, Hamzaoğlu \& Koç 540 (KNYA).

Orijinal yayında Zara ve Bolucan ile Divriği ve Sincan arasındaki aşınmış yamaçlarda, 1300-1500 metreler arasında yetiştiği tespit edilen bir Sivas endemiğidir. Yayında türün yayılış alan genişliğinin yaklaşık 100 km² olduğu hesaplanmış ve IUCN tehdit kategorisi olarak EN önerilmiştir. Ayrıca, betimlemede türün gövde boyunun 50-100 cm arasında olduğu belirtilmiştir (Yıldız et al., 2011). Yeni tespit edilen İmranlı popülasyonunda, bazı örneklerde bitki boyu $30 \mathrm{~cm}$ olarak ölçülmüştür (Şekil 3). Ayrıca İmranlı popülasyonu ile birlikte, türün yayılış alan genişliği yaklaşık $8.000 \mathrm{~km}^{2}$ olmuştur (Şekil 2). Geniş, ancak parçalı bir yayılışa sahip olması nedeniyle, türün VU kategorisinde değerlendirilmesi önerilmektedir (IUCN, 2001).

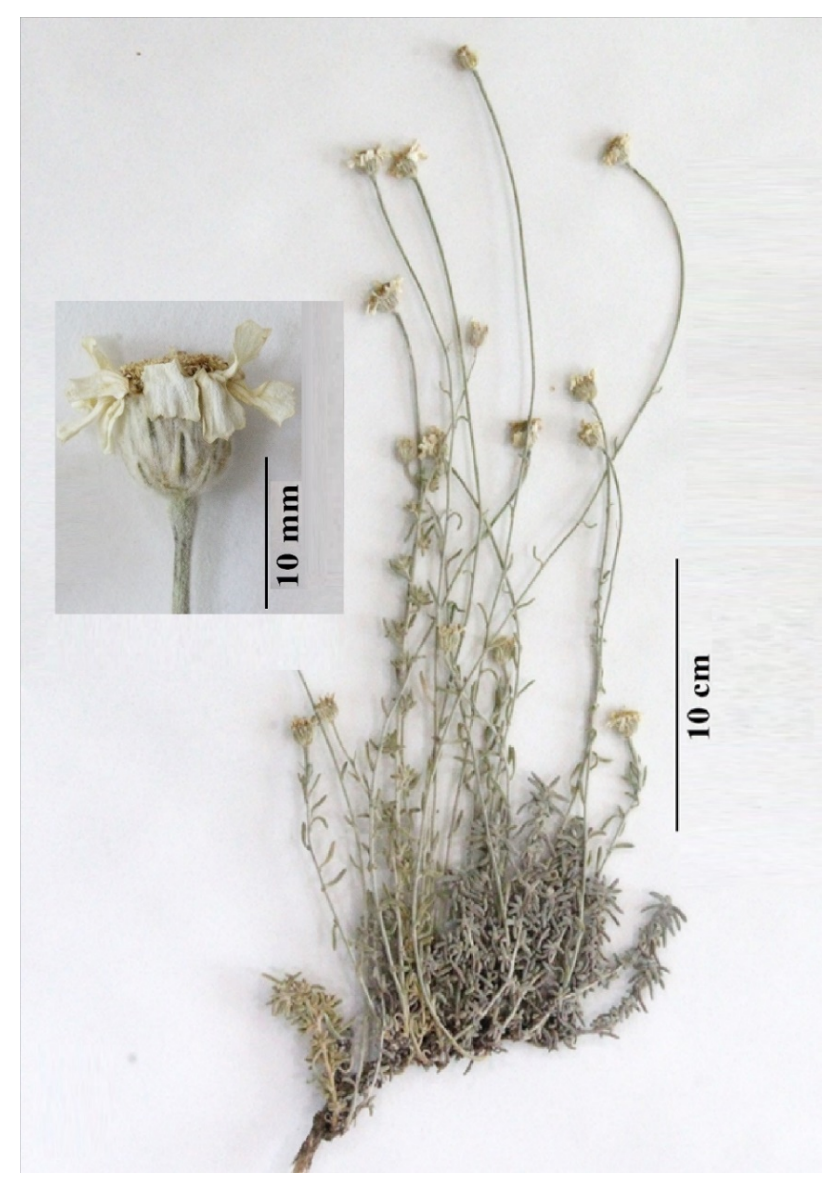

Şekil 1: Achillea formosa subsp. amanica - Habit ve kapitula.

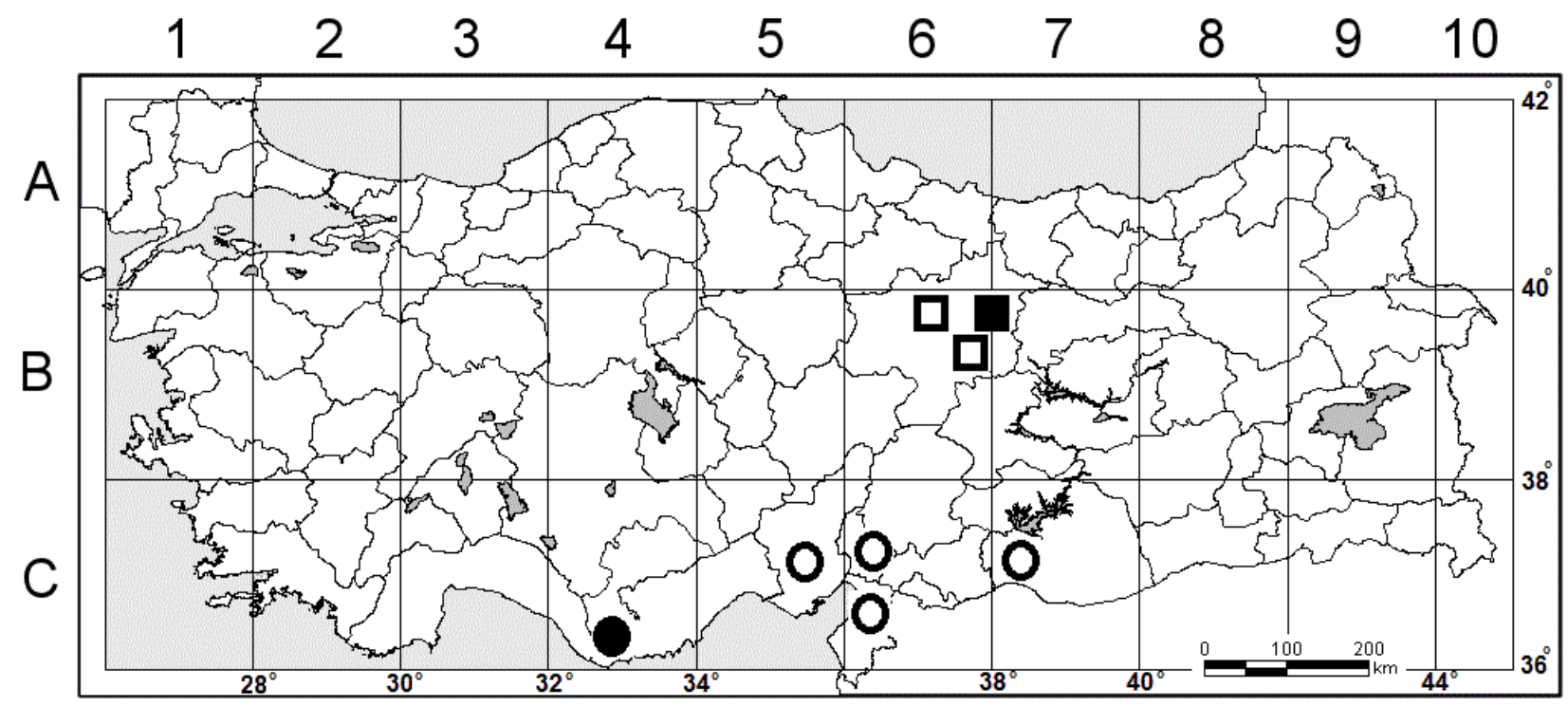

Şekil 2: Achillea formosa subsp. amanica'nın bilinen (0) ve yeni tespit edilen

, Cirsium sivasicum'un bilinen (ם) ve yeni tespit edilen (ם) popülasyonları. 


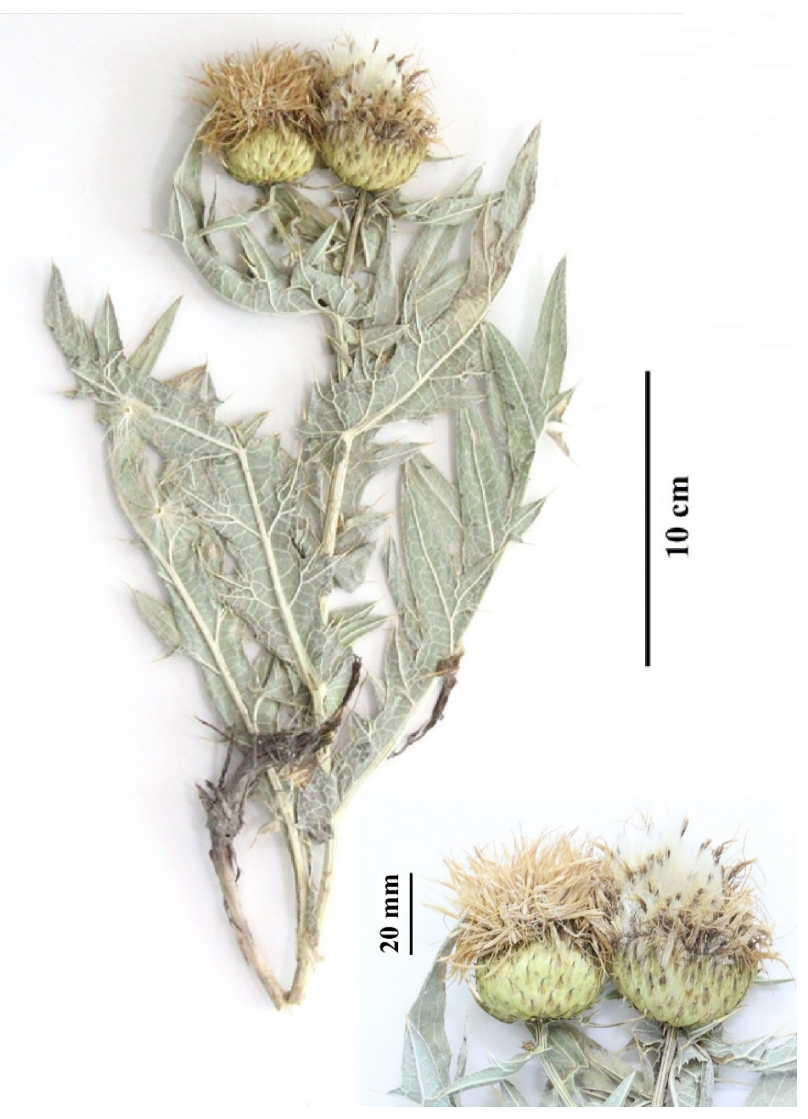

Şekil 3: Cirsium sivasicum - Habit ve kapitula.

3.1.3. Doronicum macrophyllum Fisch. ex Fisch. subsp. sparsipilosum (J.R.Edm.) Alv.Fern.

(Syn. Doronicum bithynicum J.R.Edm. subsp. sparsipilosum J.R.Edm.)

B6 Yozgat: Akdağmadeni-Şarkışla arası, Bozhüyük köyünü $3 \mathrm{~km}$ geçince, sağdaki orman yolundan c. $6.5 \mathrm{~km}$ içeri, $39^{\circ} 33^{\prime} 53^{\prime \prime} \mathrm{K}-36^{\circ} 02^{\prime} 17^{\prime \prime} \mathrm{D}, 1730 \mathrm{~m}$, orman içi dere kenarı, 15.6.2017, Hamzaoğlu \& Koç 2998 (ANK, EGE, GAZI, HUB, KNYA).

Türkiye Florası'nda verilen yayılış bilgisine göre; takson Ilgaz Dağı (Kastamonu, Çankırı) ve Ala Dağda (Bolu, Kartalkaya) yetişen bir endemiktir (Edmondson, 1975). Türkiye Florasi'nda verilen betimleme ile karşılaştırıldığında, Yozgat örneklerinde bitki boyunun daha uzun, yaprak ölçülerinin daha büyük ve kapitula sayısının daha fazla olduğu tespit edilmiştir (Şekil 4). Ilgaz Dağına göre kuşbakışı yaklaşık $250 \mathrm{~km}$ güneydoğuda tespit edilen Yozgat popülasyonu ile taksonun yayılış alan genişliği yaklaşık $50.000 \mathrm{~km}^{2}$ olmuştur (Şekil 5). Son yayılış alan genişliği dikkate alınarak, taksonun LC kategorisinde değerlendirilmesi önerilmektedir (IUCN, 2001).

\subsubsection{Galatella linosyris (L.) Rchb.f. subsp. linosyris}

A5 Sinop: Bozburun Koruma Sahası, Toykümesi mevkii, 4204'39"K-3501'37"D, $40 \mathrm{~m}$, çalı açıklığı, 27.9.2014, Hamzaoğlu 7220 (GAZI, KNYA).

Takson Batı Avrupa'dan Kafkaslara kadar yayılış gösteren bir Avrupa-Sibirya elementidir (Şekil 6). Türkiye Florası'nda verilen yayılış bilgisine İstanbul, Çanakkale ve Kocaeli'nde kıyı ve yakın kesimlerde, çalı açıklıklarında yetişmektedir (Grierson, 1975b). Kocaeli'ne göre kuşbakışı yaklaşık $450 \mathrm{~km}$ doğuda tespit edilen Sinop popülasyon ile taksonun yayılış alan genişliği yaklaşık $5.000 \mathrm{~km}^{2}$ olmuştur (Şekil 5). Mevcut veriler 1şı̆̆ında; Türkiye için endemik olmayan, ancak nadir sayllabilecek taksonun NT kategorisinde değerlendirilmesi önerilmektedir (IUCN, 2001).

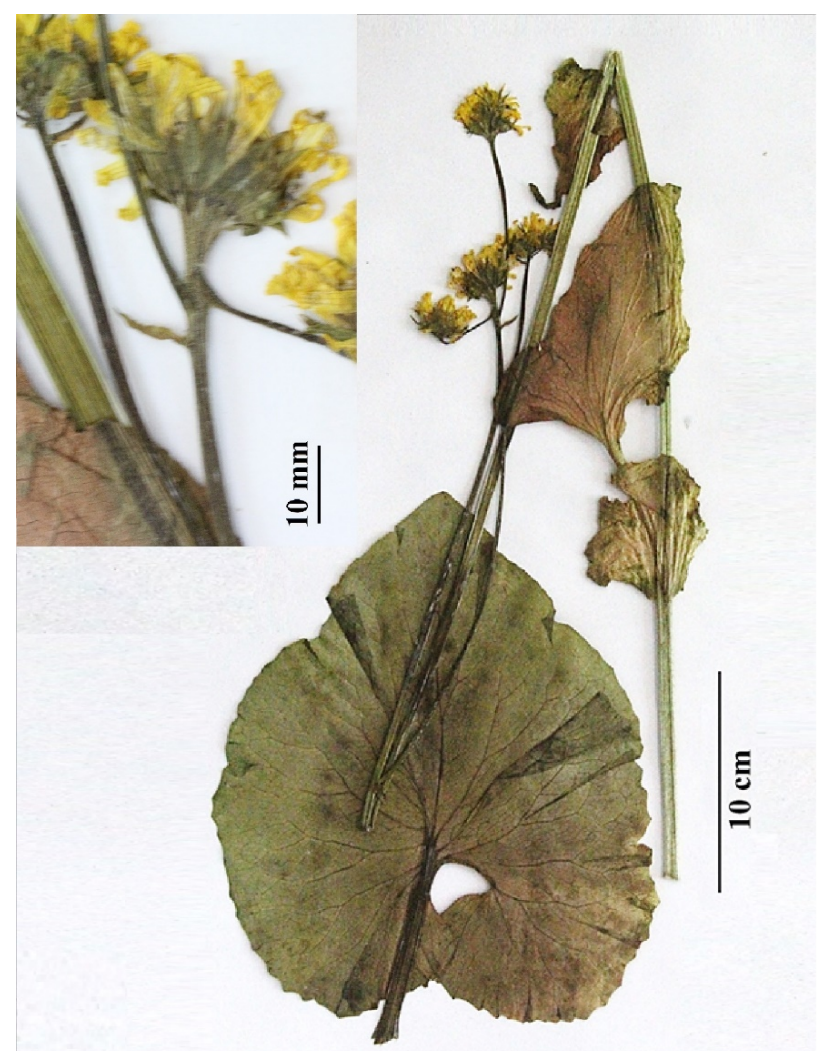

Şekil 4: Doronicum macrophyllum subsp. sparsipilosum - Habit ve kapitulum.

\subsection{Caryophyllaceae}

\subsubsection{Dianthus macroflorus Hamzaoğlu}

C4 Mersin: Gülnar, Sipahili-Beydili köyleri arası, $36^{\circ} 12^{\prime} 36^{\prime \prime K}-33^{\circ} 28^{\prime} 23^{\prime \prime} \mathrm{D}, 510 \mathrm{~m}$, konifer orman alt1, 4.10.2017, Hamzaoğlu 7405 (ISTE, KNYA); Aydıncık, Yenikaş-Karadağ köyleri arası, orman yolu, 3608'38"K$33^{\circ} 15^{\prime} 23^{\prime \prime} \mathrm{D}, 545 \mathrm{~m}$, konifer orman alt1, 5.10.2017, Hamzaoğlu 7407 (EGE, VANF).

Tür orijinal yayınında Antalya'dan (Manavgat, Akseki, Alanya), 65 metre rakımdan, maki açıklığından toplanmış holotip, izotip ve paratip örneklerle tanıtılmıştır (Hamzaoğlu et al., 2015) (Şekil 7). Mersin'de tespit edilen Gülnar ve Aydıncık popülasyonları en yakın Antalya popülasyonuna (Alanya) kuşbakışı yaklaşık $120 \mathrm{~km}$ uzaktadır. Bu iki popülasyon kaydı ile türün habitat tercihine "konifer orman" ilave edilmiş, ayrıca tercih ettiği yükselti aralığı üst sınırı 545 metreye çıkmıştır. Son popülasyon kaydı ile türün yayılış alanı genişliği yaklaşık $15.000 \mathrm{~m}^{2}$ olmuştur (Şekil 8). Geniş, ancak parçalı bir yayılışa sahip olması nedeniyle, türün VU kategorisinde değerlendirilmesi önerilmektedir (IUCN, 2001). 


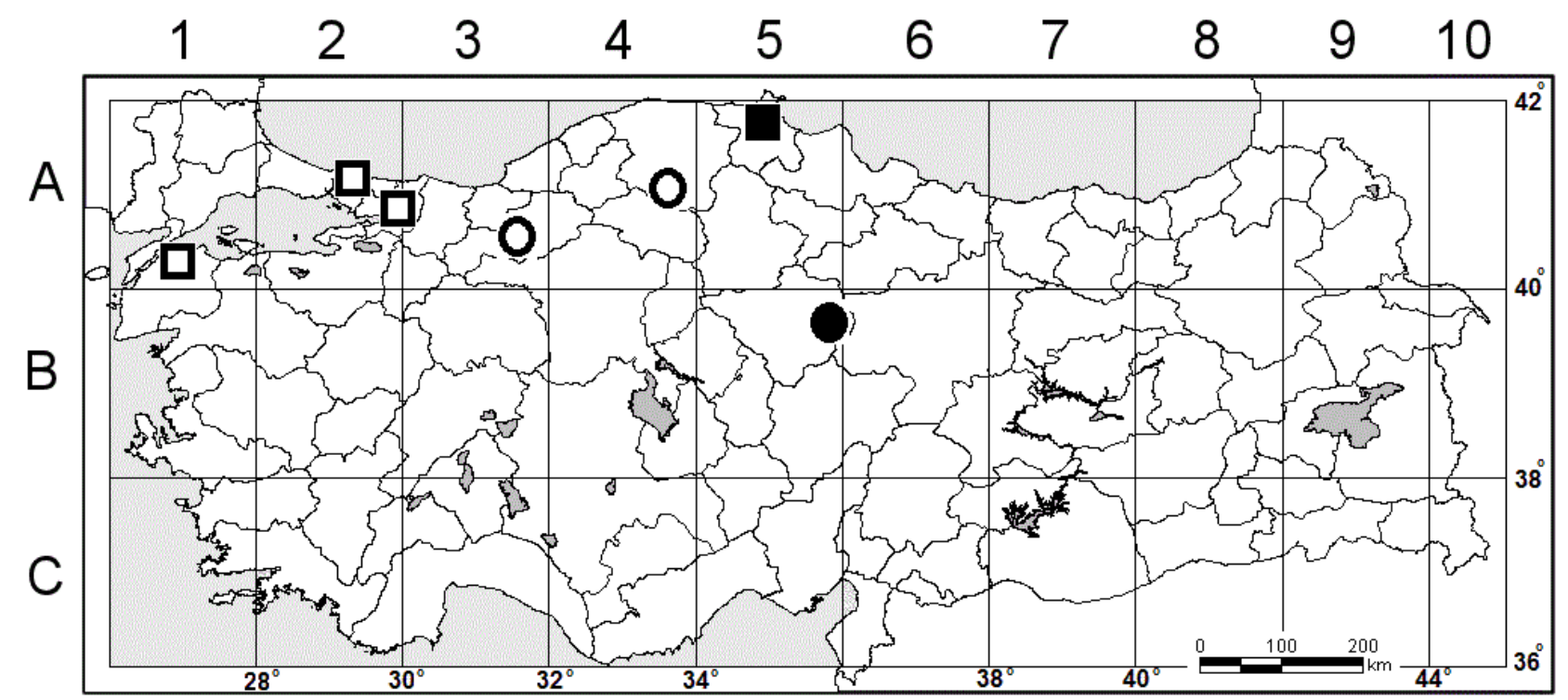

Şekil 5: Doronicum macrophyllum subsp. sparsipilosum'un bilinen $(\mathbf{O})$ ve yeni tespit edilen $(\boldsymbol{\bullet})$, Galatella linosyris'in bilinen $(\boldsymbol{(})$ ve yeni tespit edilen (ם) popülasyonları

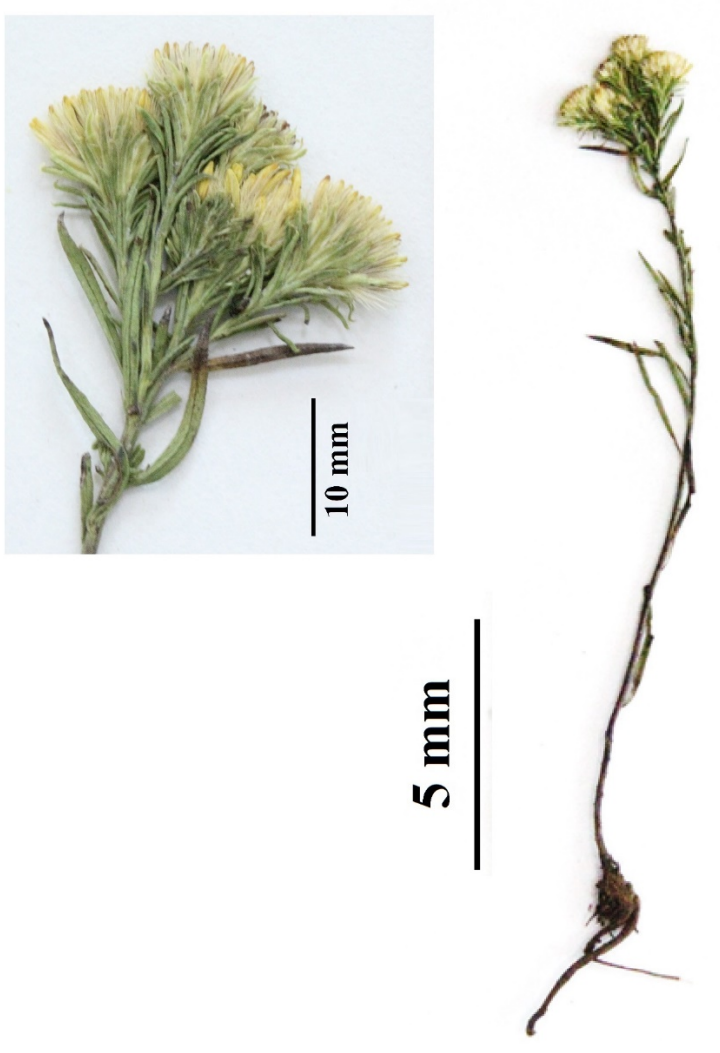

Şekil 6: Galatella linosyris - Habit ve kapitulum.

\subsubsection{Gypsophila festucifolia Hub.-Mor.}

B5 Yozgat: Şefaatli doğusu, 39³0'17"K-34²47'57"D, 930 m, marnl1-jipsli bozkır, 20.7.2017, Koç \& Hamzaoğlu 7408 (GAZI, KNYA).

Türkiye Florası'nda verilen yayılış bilgisine takson Sivas (Tecer ve Kangal) ve Kayseri'de (Tomarza, Arslantaş) marnlı yamaçlarda, 1500-1550 metre yükselti aralığında yetişen bir endemiktir (Huber-Morath, 1967) (Şekil 9). Sivas popülasyonlarına göre kuşbakışı yaklaşık $220 \mathrm{~km}$ kuzeybatıda, Kayseri popülasyonuna göre ise kuşbakışı yaklaşık $170 \mathrm{~km}$ kuzeybatıda tespit edilen Şefaatli
(Yozgat) popülasyonu ile türün yükselti tercihi alt sinırı 930 metreye düşmüştür. Son popülasyon verisi ile birlikte türün yayılış alanı genişliği yaklaşık 20.000 km² olmuştur (Şekil 8). Sivas, Çorum, Çankırı, Yozgat ve Kayseri civarlarında marnl1-jipsli bozkır habitatlarına sıklıkla rastlanması, türün yayılış alanının bilinenden daha geniş olabileceğini göstermektedir. Son veriler ve yorumlar göz önüne alınarak, türün NT kategorisinde değerlendirilmesi önerilmektedir (IUCN, 2001).

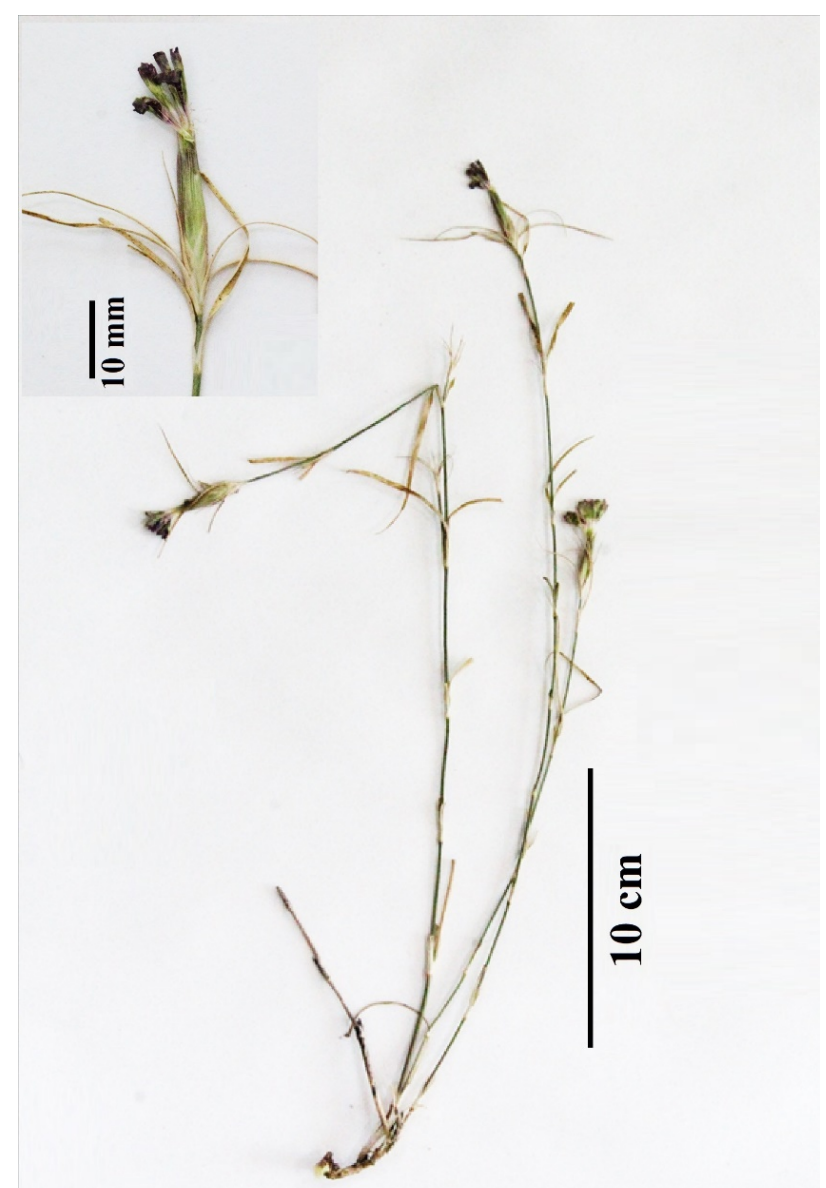

Şekil 7: Dianthus macroflorus - Habit ve çiçek. 


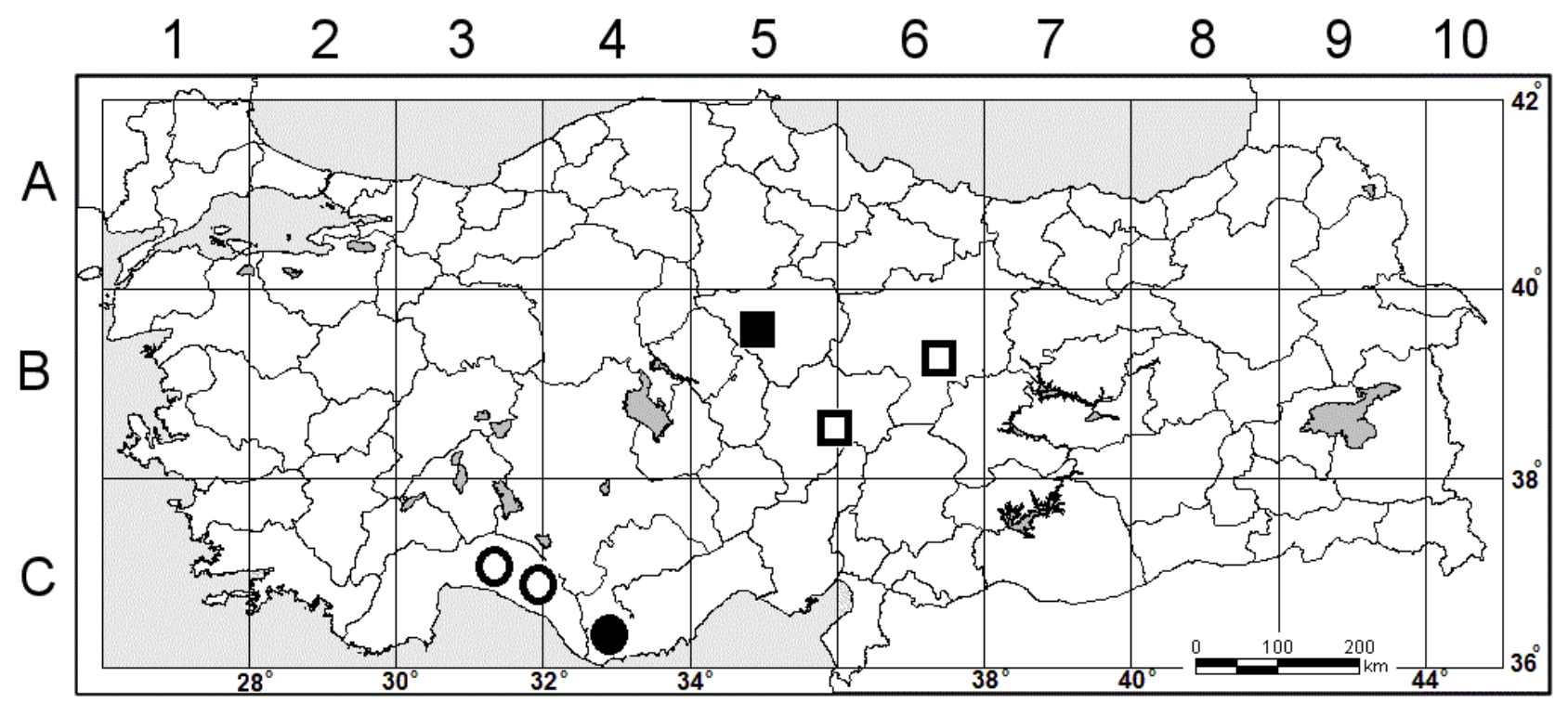

Şekil 8: Dianthus macroflorus'un bilinen (0) ve yeni tespit edilen popülasyonları

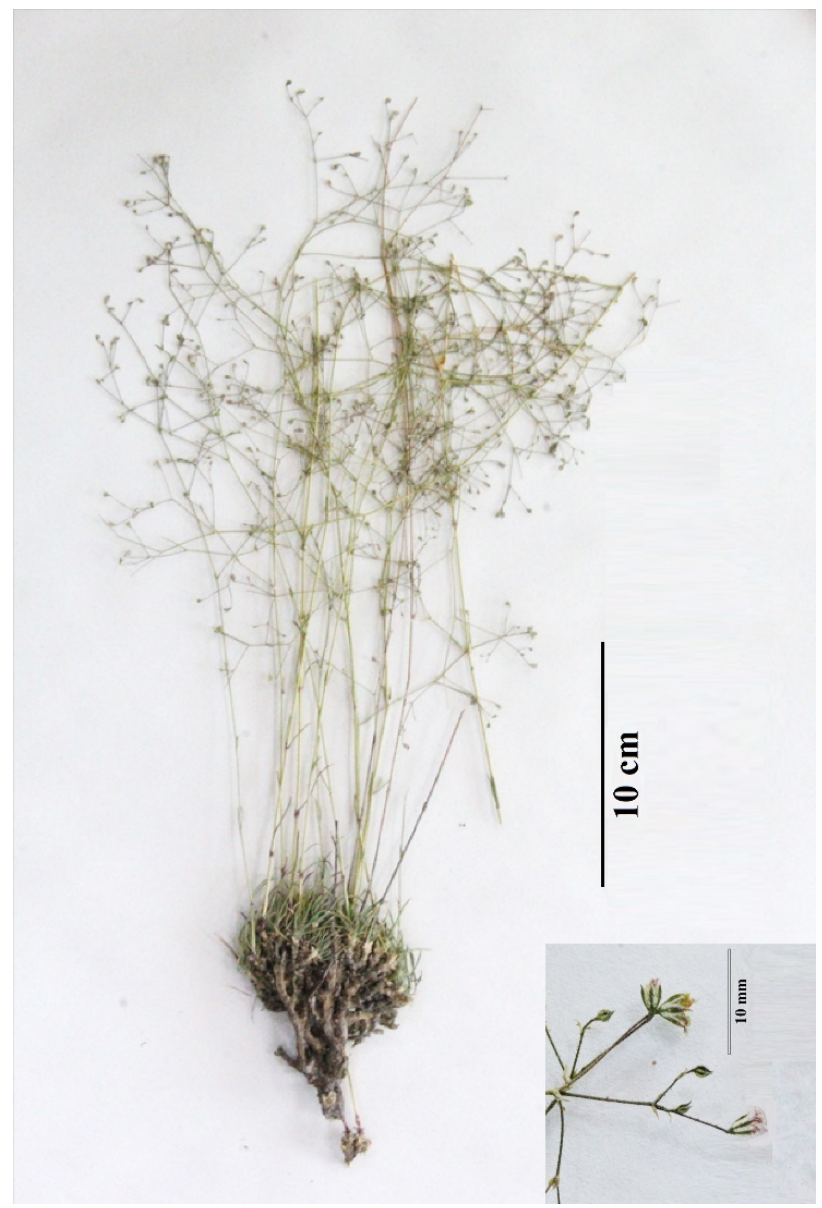

Şekil 9: Gypsophila festucifolia - Habit ve çiçekler.

\subsection{Ranunculaceae}

\subsubsection{Delphinium cinereum Boiss.}

B5 Yozgat: Yerköy, Terzili ve Kayadibi köyleri yol ayrımları arası, $39^{\circ} 49^{\prime} 20^{\prime \prime} \mathrm{K}-34^{\circ} 10^{\prime} 58^{\prime \prime} \mathrm{D}, 730 \mathrm{~m}$, tuzlu bozkır, 6.7.2016, Koç \& Hamzaoğlu 7236 (ANK, EGE, GAZI, HUB, ISTE, ISTO, KNYA, VANF).
Türkiye Florası'nda verilen yayılış bilgisine göre takson Denizli (tip adres) ve Konya'da (Karapınar) yetişen bir endemiktir (Şekil 10). Türün Konya (Karapınar) örneği görülmemiştir (Davis, 1965a). Türkiye Florası'nda belirtilmemiş olmasına karşın, Yozgat popülasyonuna dayanarak türün tuzlu düzlükleri tercih ettiği söylenebilir. Denizli popülasyonuna göre kuşbakışı yaklaşık 500 km kuzeydoğuda ve Konya (Karapınar) popülasyonuna göre $230 \mathrm{~km}$ kuzeyde tespit edilen Yozgat (Yerköy) popülasyonu ile türün yayılış alanı genişliği yaklaşık $30.000 \mathrm{~km}^{2}$ olmuştur (Şekil 11). Tuzlu düzlüklerin, drenajla tuzdan arındırılarak tarıma kazandırılma ihtimali yüksek olduğundan, türün NT kategorisinde değerlendirilmesi önerilmektedir (IUCN, 2001).

\subsubsection{Ranunculus flammula L. var. ovalis (J.M.Bigelow)} L.D.Benson

B4 Aksaray: Eskil'in doğusu, Tuz Gölü'ne doğru giden

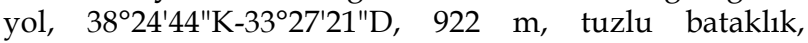
4.6.2008, Koç \& Hamzaoğlu 5379 (ANK, EGE, GAZI, HUB, ISTE, ISTO, KNYA, VANF).

Takson Türkiye Florası'nda Kars [Ardahan] Hanak yakını ve Konya'dan (Murat su) toplanmış, ancak görülmemiş iki örnekle tanıtılmıştır (Şekil 12). Ayrıca takson alttür veya varyetelere ayrılmadan tür düzeyinde verilmiştir (Davis, 1965b). Eskil popülasyonuna ait örnekler detaylı olarak incelendiğinde, bunların "var. ovalis" olduğu kanaatine varılmıştır (Tutin \& Akeroyd, 1993; Whittemore, 1997; Prati \& Peintinger, 2000). Eskil popülasyonunun tespiti ile taksonun Türkiye'de yetiştiği kesinlik kazanmıştır. Görülmeyen Ardahan ve Konya örnekleri türün Türkiye yayılış alanına dâhil edilmemiş, mevcut veriler ışığında türün sadece Tuz Gölü güneyinde tuzlu bataklıklarda yetiştiği kabul edilmiştir (Şekil 11). Mevcut veriler ışığında; Türkiye için endemik olmayan, ancak nadir sayılabilecek taksonun yoğun antropojen etkiler nedeniyle EN kategorisinde değerlendirilmesi önerilmektedir (IUCN, 2001). 


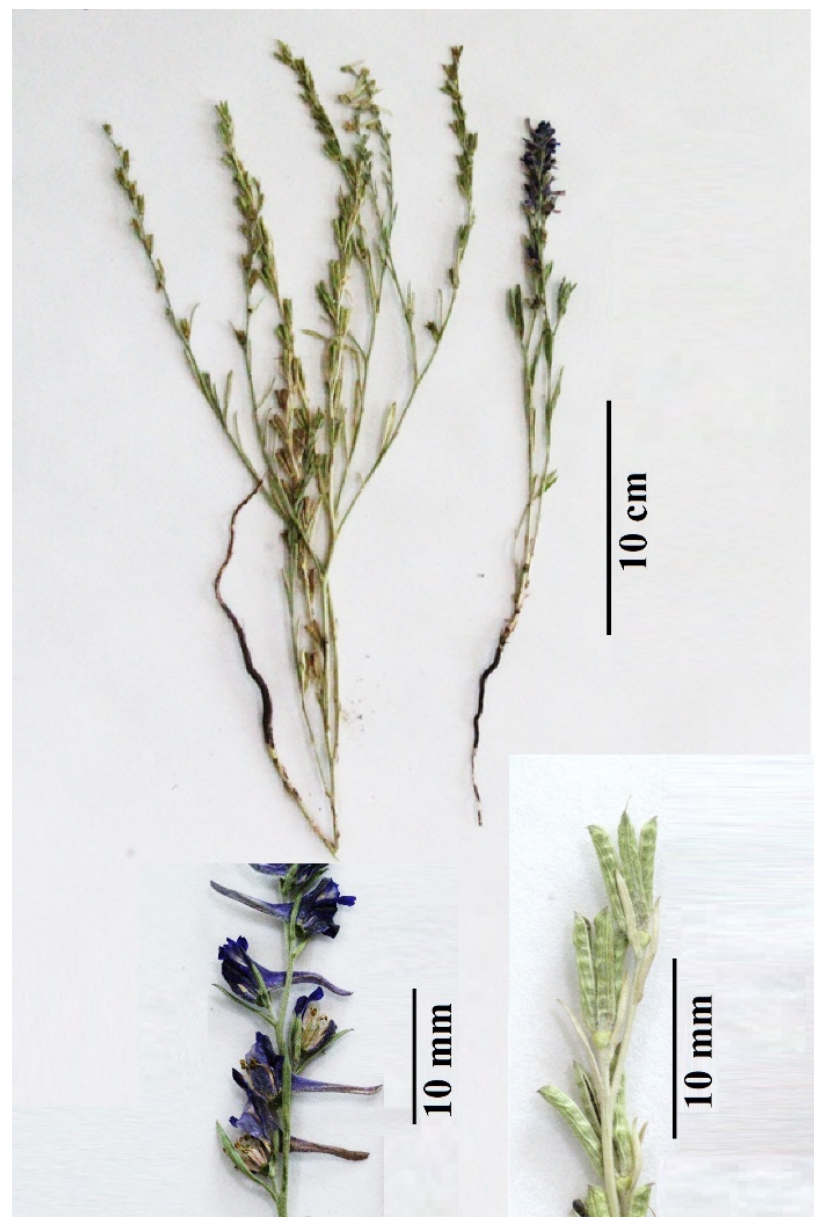

Şekil 10: Delphinium cinereum -Habit, çiçekler ve meyveler.

\subsection{Boraginaceae}

\subsubsection{Onosma nigricaulis Riedl}

A9 Ardahan: Çıldır, Yıldırımtepe köyü, Şeytan Kalesi

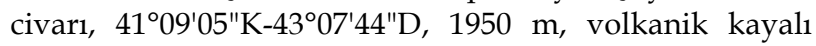

otlu yamaçlar, 4.7.2013, Koç \& Hamzaoğlu 6814 (GAZI, KNYA).

Türkiye Florası'nda verilen yayılış bilgisine takson sadece Sarıkamış-Selim (Kars) arasında, çayır ve volkanik yamaçlar, yaklaşık 1900 metre yükseltide yetişen ve sadece tip adresinden bilinen bir dar endemiktir (Riedl, 1978) (Şekil 13). Tip adresine göre kuşbakışı yaklaşık 90 $\mathrm{km}$ kuzeydoğuda tespit edilen Çıldır (Ardahan) popülasyonu ile türün yayılış alanı genişliği yaklaşık $5.000 \mathrm{~km}^{2}$ olmuştur (Şekil 14). Tercih ettiği habitat ve yükseltinin antropojen etkiye maruz kalma ihtimali düşük olduğundan, türün VU kategorisinde değerlendirilmesi önerilmektedir (IUCN, 2001).

\subsection{Brassicaceae}

\subsubsection{Sisymbrium malatyanum Mutlu \& Karakuş}

B6 Malatya: Darende, Çukurkaya köyü üstü, vadi içi, 38 38'14"K-37²8'48"D, $1150 \mathrm{~m}$, gölgeli kalker mağara ağızları, 12.7.2012, Koç \& Hamzaoğlu 6464 (ANK, GAZI, KNYA).

Tür orijinal yayınında Malatya Akçadağ Bayramuşağı köyünden toplanmış örneklerle tanıtılmıştır (Mutlu \& Karakuş, 2015) (Şekil 15). Malatya Darende'de tespit edilen popülasyon, Akçadağ popülasyonunun kuşbakışı yaklaşık $45 \mathrm{~km}$ kuzeybatısındadır (Şekil 14). Her iki popülasyonun mağara ağızlarını tercih etmesi, türün seçici olduğunu göstermektedir. Son popülasyon tespiti ile birlikte türün yayılış alanı genişliği yaklaşı 3.000 km² olmuştur. Yayılış alan genişliği ve tercih ettiği habitatın özgünlüğü dikkate alınarak, türün EN kategorisinde değerlendirilmesi önerilmektedir (IUCN, 2001).

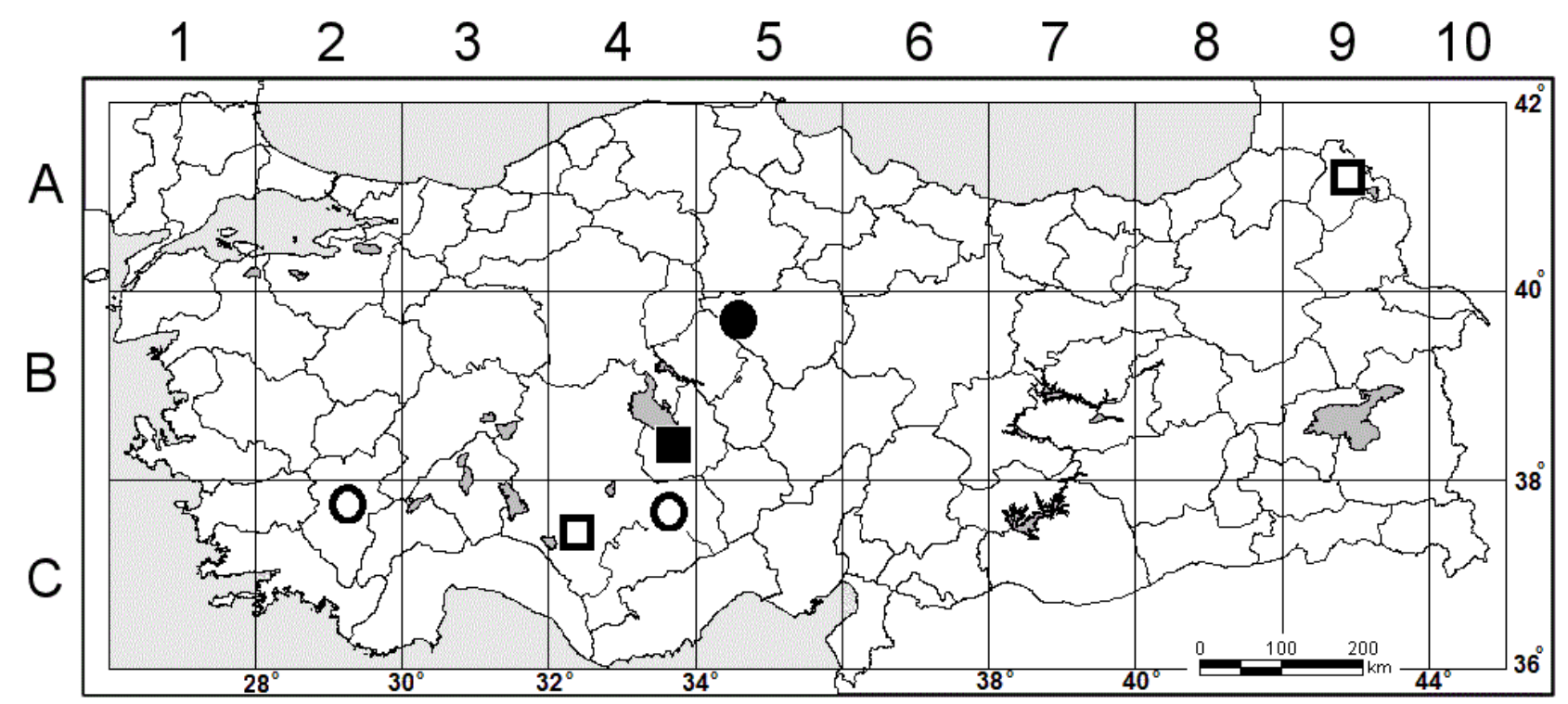

Şekil 11: Delphinium cinereum' un bilinen $(\mathbf{O})$ ve yeni tespit edilen (

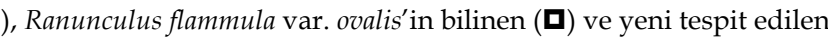
(ם) popülasyonları. 


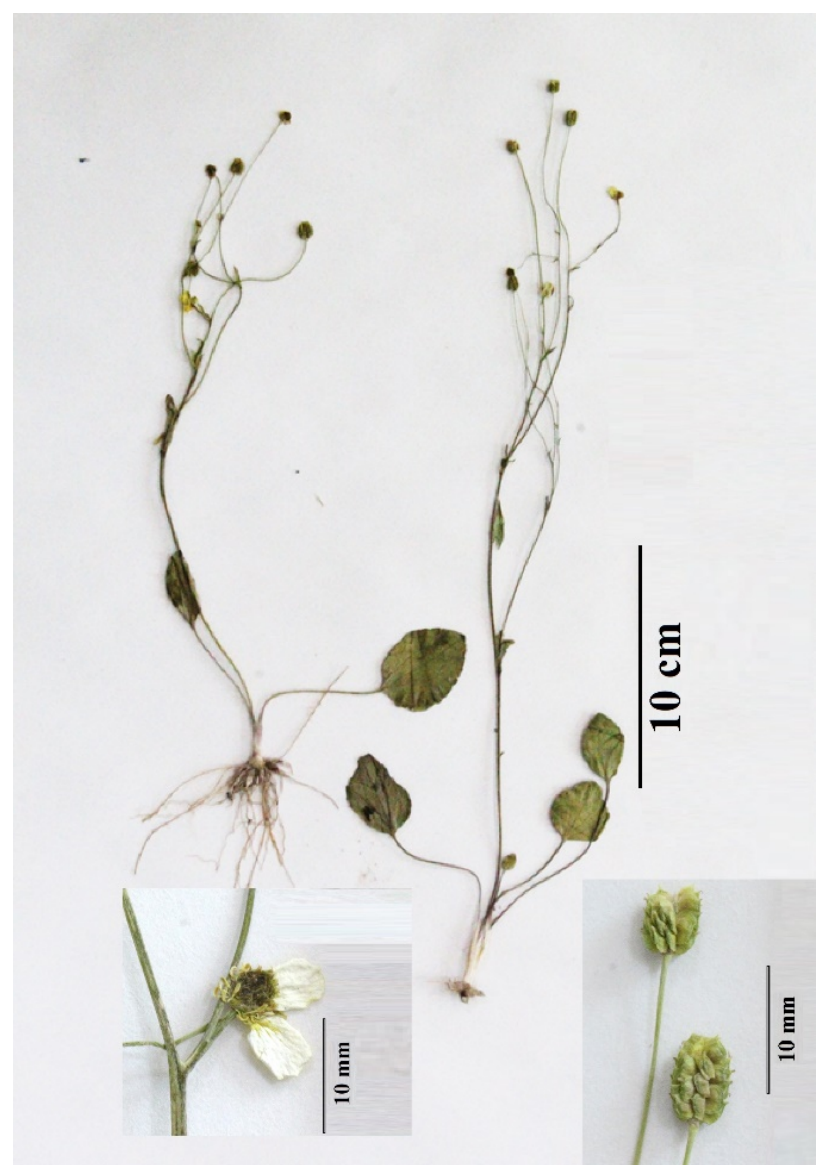

Şekil 12: Ranunculus flammula var. ovalis - Habit, çiçek ve meyveler.

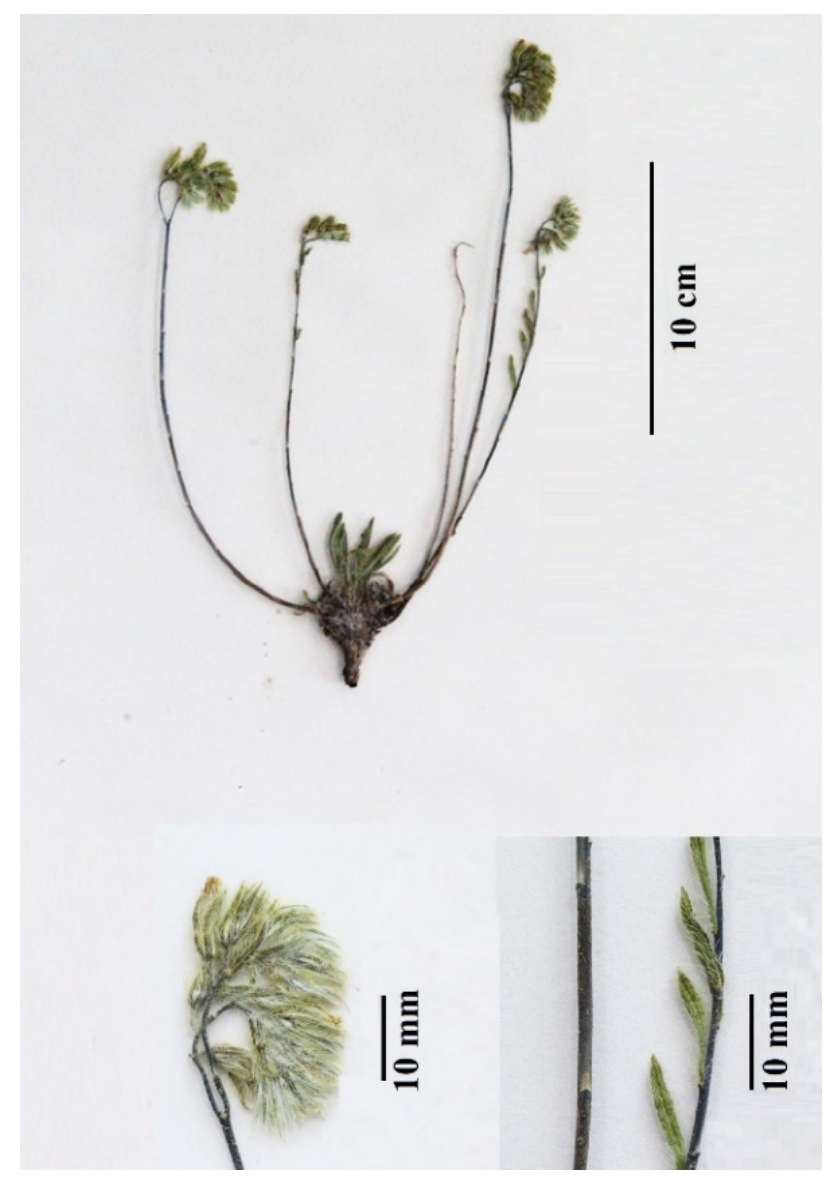

Şekil 13: Onosma nigricaulis -Habit, çiçekler ve gövde.

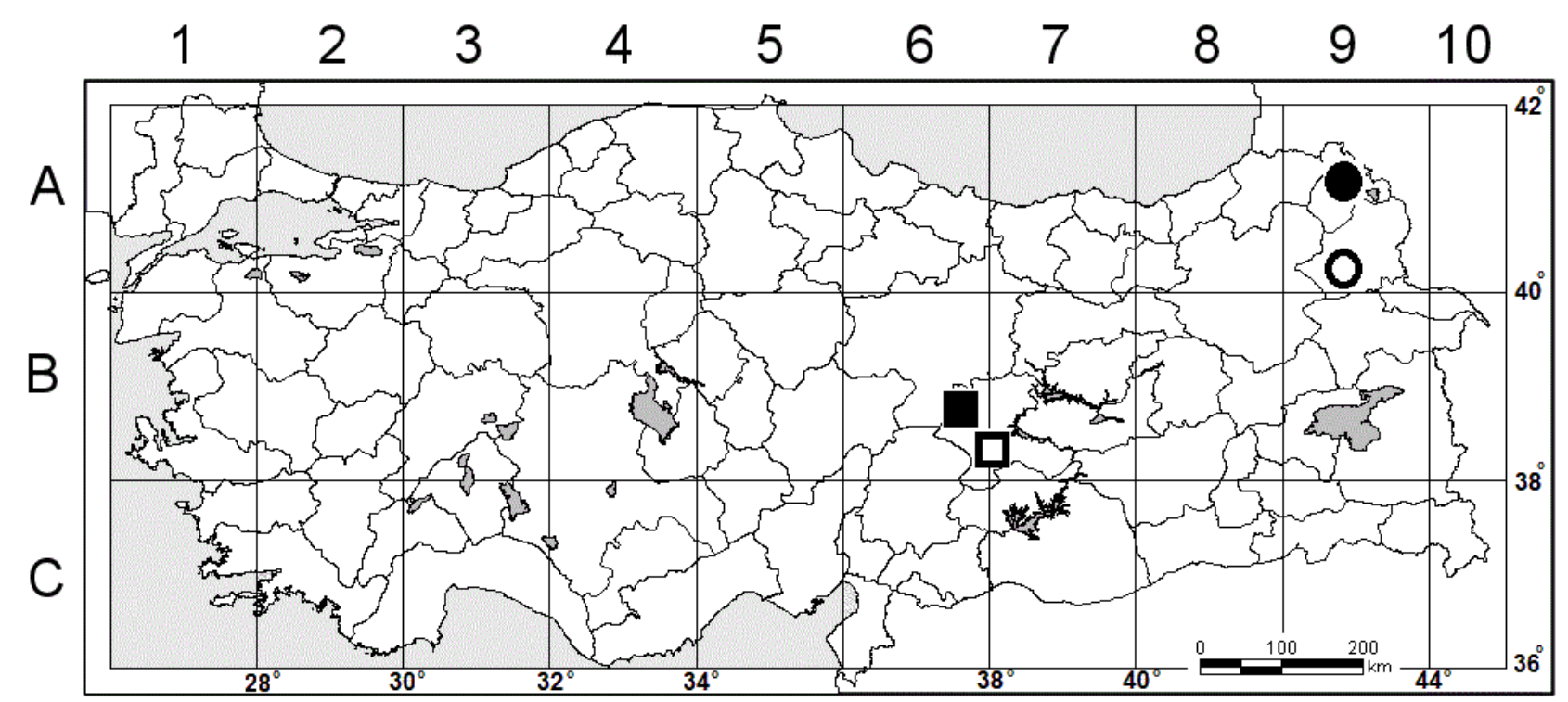

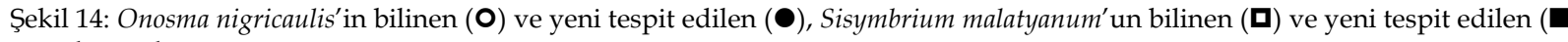
popülasyonları. 


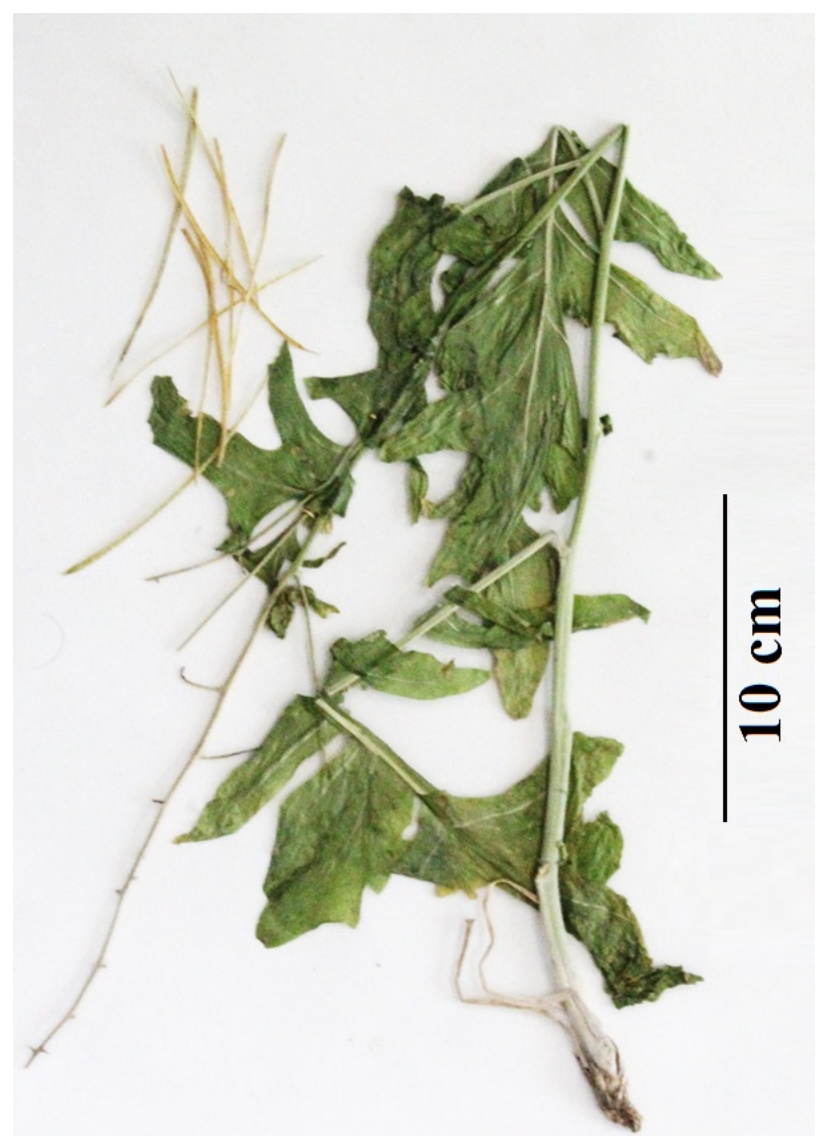

Şekil 15: Sisymbrium malatyanum - Habit ve meyveler.

\subsection{Cistaceae}

\subsubsection{Tuberaria guttata (L.) Fourr.}

A5 Sinop: İnceburun yolu, Bozburun Koruma Sahası, 4204'04"K-3459'58"D, 70 m, maki açıklığı, 11.6.2016, Koç \& Hamzaoğlu 7242 (ANK, EGE, GAZI, HUB, ISTE, ISTO, KNYA, VANF).

Takson Türkiye Florası'nda Antalya, Çanakkale ve İstanbul'dan toplanmış üç örnekle tanıtılmıştır (Şekil 16). $\mathrm{Bu}$ örneklerden sadece Antalya (Manavgat to Kara, 3 m, Davis 25836) görülmüştür (Hedge, 1965). Sinop popülasyonu, Çanakkale ve Antalya popülasyonlarına kuşbakışı yaklaşık $700 \mathrm{~km}$ ve İstanbul (Büyükada) popülasyonuna yaklaşık $500 \mathrm{~km}$ mesafededir (Şekil 17). Kıyı ve yakın kesimleri tercih eden ve parçalı bir dağılış gösteren türün, son popülasyon verisiyle birlikte yayılış alan genişliği yaklaşık $25.000 \mathrm{~km}^{2}$ olmuştur. Türkiye için endemik olmayan, ancak nadir sayılabilecek taksonun NT kategorisinde değerlendirilmesi önerilmektedir (IUCN, 2001).

\subsection{Convolvulaceae}

\subsubsection{Convolvulus oleifolius Desr. var. deserti Pamp.}

C4 Mersin: Gülnar, Büyükeceli köyü, Beşparmak Adası, 3607'19"K-3331'59"D, 30 m, kalker kayalıklar, 28.5.2011, Hamzaoğlu 6091 (ANK, GAZI, KNYA, ISTE, VANF).

Genel olarak İtalya (Sicilya), Yunanistan, Malta, Ege Adaları, Türkiye, Kıbrıs, Misır, Libya, Filistin, Kuzey Afrika ve Suriye'nin batısında yetişen takson Türkiye'de İzmir, Muğla ve Antalya'dan bilinen bir Akdeniz elementidir (Parris, 1978; Aykurt \& Sümbül, 2010) (Şekil 18). Mersin popülasyonu, en yakın popülasyona (Antalya, Finike) kuşbakışı yaklaşık 320 km doğudadır.
Popülasyon, hem Mersin ili hem de Türkiye Akdeniz adaları için yenidir. $\mathrm{Bu}$ yeni popülasyon bilgisiyle taksonun yayılış alan genişliği yaklaşık $30.000 \mathrm{~km}^{2}$ olmuştur. Taksonun genel yayılışa uygun olarak Türkiye yayılışını Suriye'ye doğru genişlettiği anlaşılmıştır (Şekil 17). Türkiye için endemik olmayan, ancak nadir sayllabilecek taksonun NT kategorisinde değerlendirilmesi önerilmektedir (IUCN, 2001).

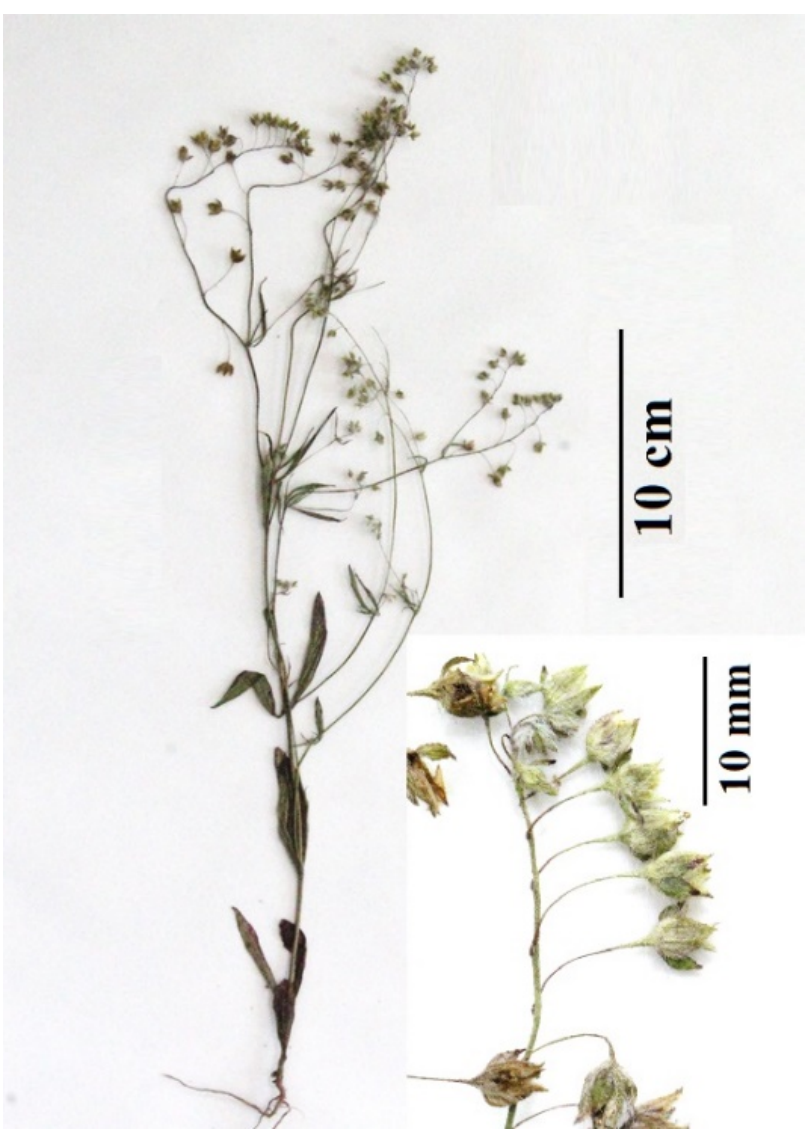

Şekil 16: Tuberaria guttata - Habit ve çiçekler.

\subsection{Caprifoliaceae}

\subsubsection{Cephalaria aytachii Göktürk \& Sümbül}

B2 Kütahya: Bozüyük yolu, Gevrekseydi köyü kuzeyi, 39³2'43"K-2951'38"D, $1090 \mathrm{~m}$, marnl1-jipli bozkir, 5.8.2018, Koç \& Hamzaoğlu 7505 (GAZI, ANK, HUB, KNYA); B3 Eskişehir: Odunpazarı, Kireçköy yakını, 3945'56"K-3046'51"D, 920 m, marnl1-jipsli kayalık, bozkır, 30.7.2017, Hamzaoğlu 7336 (GAZI); Beylikova, Doğanoğlu-Ağaçhisar köyleri arası, dağ yolu, 3952'42"K-

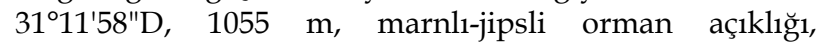
31.7.2017, Hamzaoğlu 7332 (GAZI); aynı yer, Doğanoğlu köyü kuzeyi, ağaçlandırma sahası, 3949'56"K-3112'58"D, 910 m, marnl1-jipsli bozkır, 31.7.2017, Hamzaoğlu 7337 (GAZI); aynı yer, Bozan-Doğanoğlu köyleri arası, yolun sağı, ağaçlandırma sahası, 39²4'37"K-3108'44"D, 880 m, marnl1-jipsli bozkır, 31.7.2017, Hamzaoğlu 7339 (GAZI).

Tür orijinal yayınında "Eskişehir, Sivrihisar, Așağıkepen köyü" civarında, marnlı-jipsli yamaçlarda, 900-950 metre aralığında toplanmış örneklerle tanıtılmıştır (Göktürk \& Sümbül, 2003) (Şekil 19). Eskişehir Kireçköy (Odunpazarı), Doğanoğlu köyü (Beylikova) ve Kütahya (Gevrekseydi) civarında türe ait üç yeni popülasyon tespit edilmiştir (Şekil 20). Tip adresine göre kuşbakışı yaklaşık 200 km güneybatıda tespit edilen Kütahya ve 80 $\mathrm{km}$ kuzeybatıda tespit edilen Eskişehir bu yeni üç 
popülasyon ile birlikte, türün yayılış alan genişliği yaklaşık $15.000 \mathrm{~km}^{2}$ olmuştur. Ankara, Kütahya ve Afyonkarahisar civarlarında marnl1-jipsli habitatlara sıklıkla rastlandığı göz önüne alınarak, türün yayılış alan genişliğinin bilinenden daha fazla olduğu söylenebilir. Mevcut popülasyon verileri ve yorumlar dikkate alınarak, türün VU kategorisinde değerlendirilmesi önerilmektedir (IUCN, 2001).

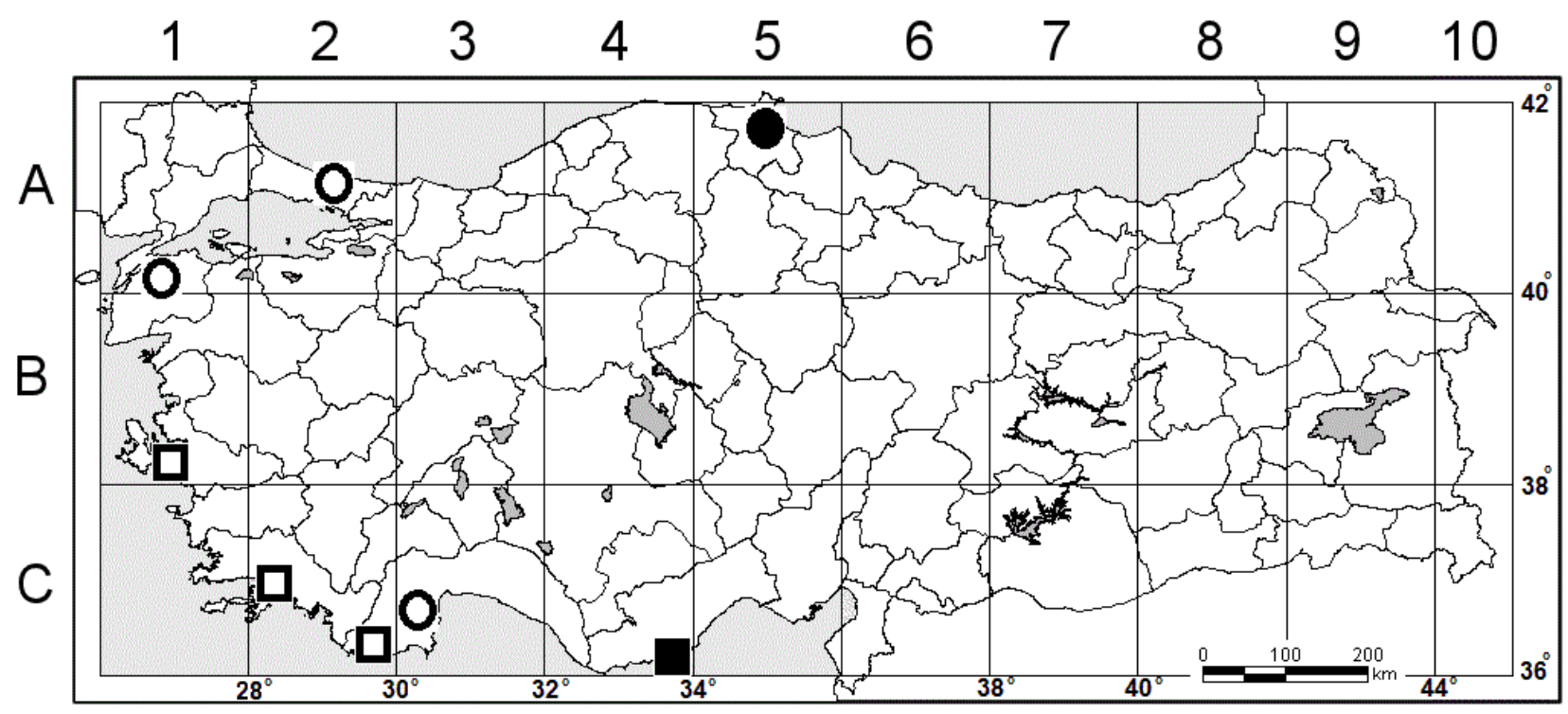

Şekil 17: Tuberaria guttata'nın bilinen $(\mathbf{O})$ ve yeni tespit edilen

), Convolvulus oleifolius var. deserti'nin bilinen ( $\mathbf{\square})$ ve yeni tespit edilen (ם) popülasyonları.

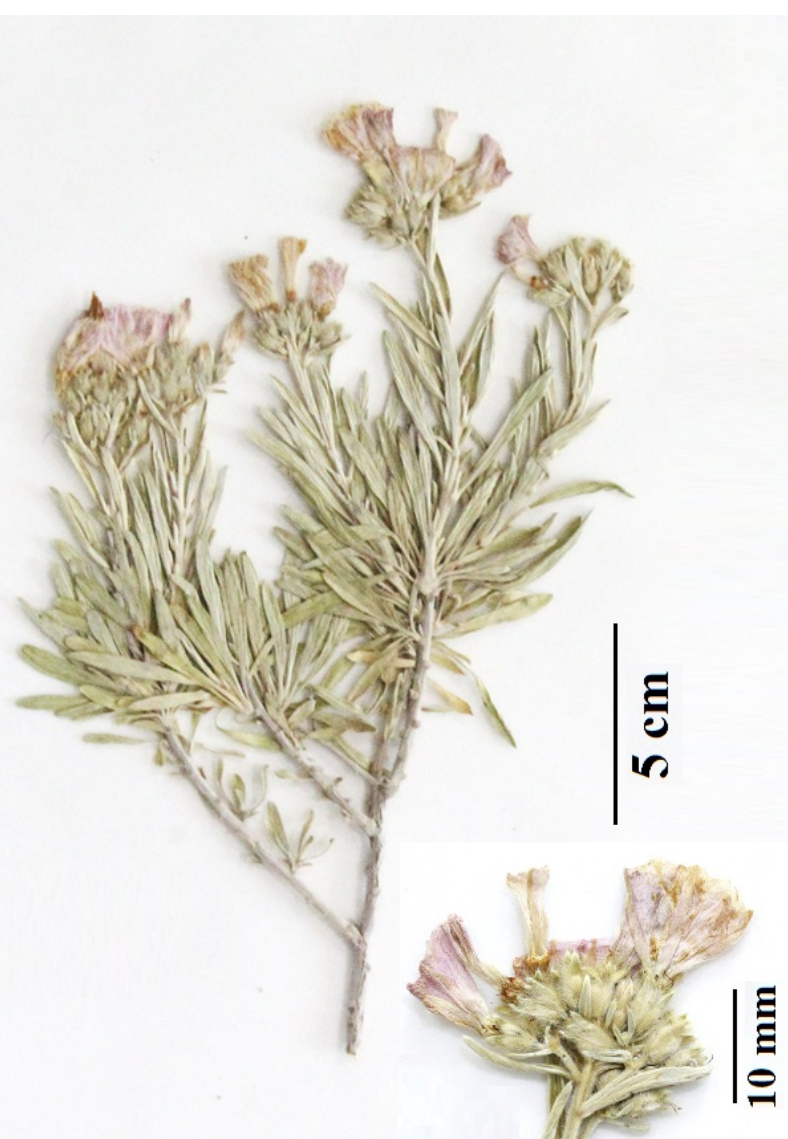

Şekil 18: Convolvulus oleifolius var. deserti - Habit ve çiçekler.

\subsection{Fabaceae}

\subsubsection{Astragalus polemoniacus Bunge}

B5 Yozgat: Yerköy, Derebağ1 köyü yakını, 3952'41"K3406'49"D, 780 m, jipsli bozkır, 18.5.2017, Hamzaoğlu \& Koç 2490 (GAZI).

Türkiye Florası'nda verilen ve sonradan tespit edilen popülasyon bilgilerine göre takson Tokat, Samsun, Amasya ve Kirıkkale'den bilinen bir endemiktir (Chamberlain \& Matthews, 1970; Karaer et al., 2015) (Şekil 21). Burada adresi verilen Yozgat popülasyonu ile taksonun ilk kez tanımlandığı Tokat ve Samsun'a göre Kırıkkale-Yozgat arasındaki jipsli bozkırlarda daha geniş bir yayılışa sahip olduğu anlaşılmıştır (Şekil 20). Bu yeni popülasyon bilgileri ile birlikte, türün yayılış alan genişliği yaklaşık $20.000 \mathrm{~km}^{2}$ olmuştur. Son veriler ışığında taksonun NT kategorisinde değerlendirilmesi önerilmektedir (IUCN, 2001).

\section{Tartışma}

Asteraceae (4), Caryophyllaceae (2), Ranunculaceae (2), Boraginaceae (1), Brassicaceae (1), Cistaceae (1), Convolvulaceae (1), Caprifoliaceae (1) ve Fabaceae (1) familyalarına ait toplam 14 endemik ve/veya nadir takson için yeni popülasyon bilgileri verilmiş ve böylece taksonların yayılış alanı genişletilmiştir. Yayılış alanı genişlemiş olan taksonlar için; önceden belirlenen ve bu çalışmada önerilen IUCN tehdit kategorileri Tablo 1'de verilmiştir (Ekim et al., 2000; Göktürk \& Sümbül, 2003; Yildız et al., 2011; Hamzaoğlu et al., 2015; Mutlu \& Karakus, 2015; Karaer et al., 2015). Endemik olmayan 4 takson ilk kez burada "nadir" olarak değerlendirildi ve bunlardan Ranunculus flammula var. ovalis için EN, Galatella linosyris subsp. linosyris, Tuberaria guttata ve Convolvulus oleifolius var. deserti içinse NT tehdit kategorileri önerildi (Tablo 1). Yeni popülasyon 
kayıtlarından sonra tehdit kategorileri; Astragalus polemoniacus'da üç basamak, Cephalaria aytachii'de iki basamak, Achillea formosa subsp. amanica, Cirsium sivasicum, Dianthus macroflorus, Gypsophila festucifolia, Delphinium cinereum ve Sisymbrium malatyanum'da bir basamak düşürülmüş, Doronicum macrophyllum subsp. sparsipilosum ve Onosma nigricaulis'te ise değiştirilmemiştir.

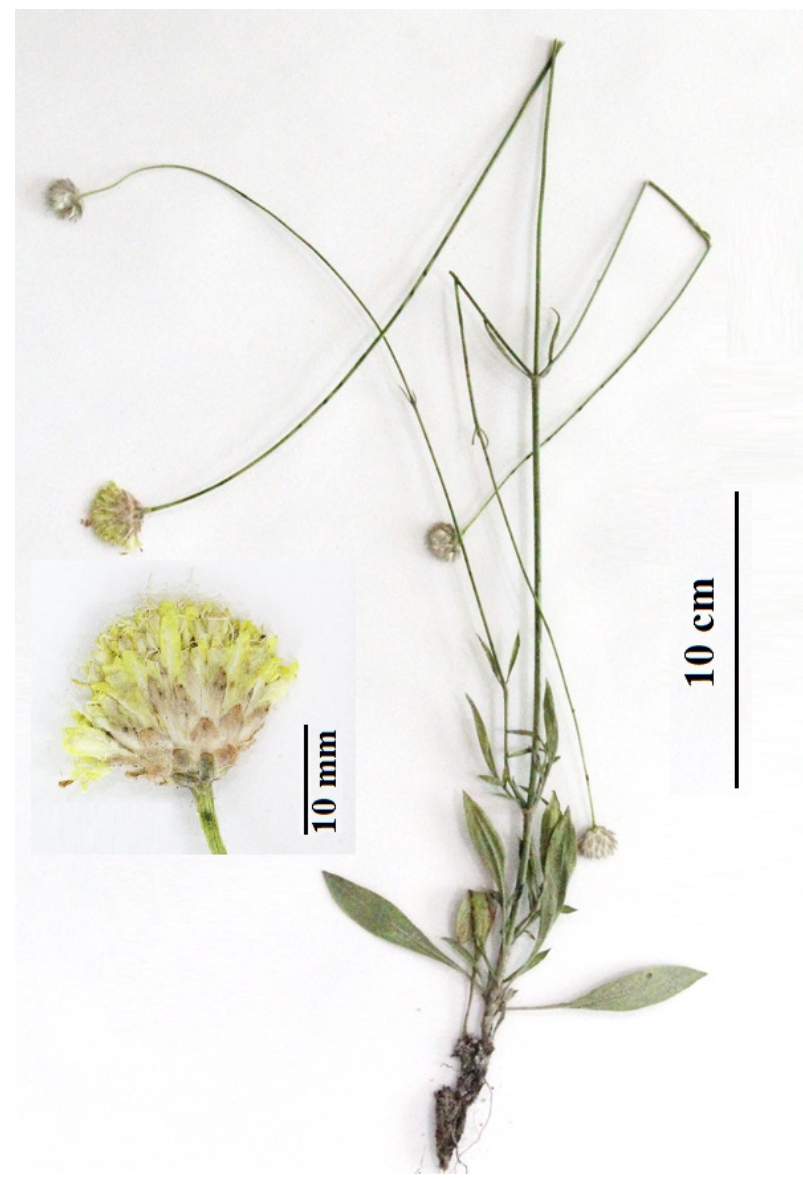

Şekil 19: Cephalaria aytachii - Habit ve kapitula

Yozgat'tan toplanan Doronicum macrophyllum subsp. sparsipilosum (Syn. D. bithynicum subsp. sparsipilosum) örnekleri, bazı karakterler bakımından Türkiye
Florası'nda verilen betimlemeden farklılıklar göstermektedir (Edmondson, 1975). Bu farklılıkların yeni bir taksona karşılık gelip gelmediği detaylı araştırmaya muhtaçtır. Eskil popülasyonu verilen Ranunculus flammula örnekleri birçok araştırıcı tarafından toplanmış ve hatta yeni bir takson olduğu zanniyla üzerinde uğraş verilmiştir. Yapılan literatür çalışması sonucu, bu örneklerin türün Kuzey Amerika'da yayılış gösteren bir varyetesi (var. ovalis) olduğu anlaşılmıştır (Whittemore, 1997). Kuzey Amerika'da sulak habitatlarda yayılış gösteren bu örneklerin, Eskil çevresindeki tuzcul bataklıklara göçmen su kuşları tarafından taşındığı düşünülmektedir.

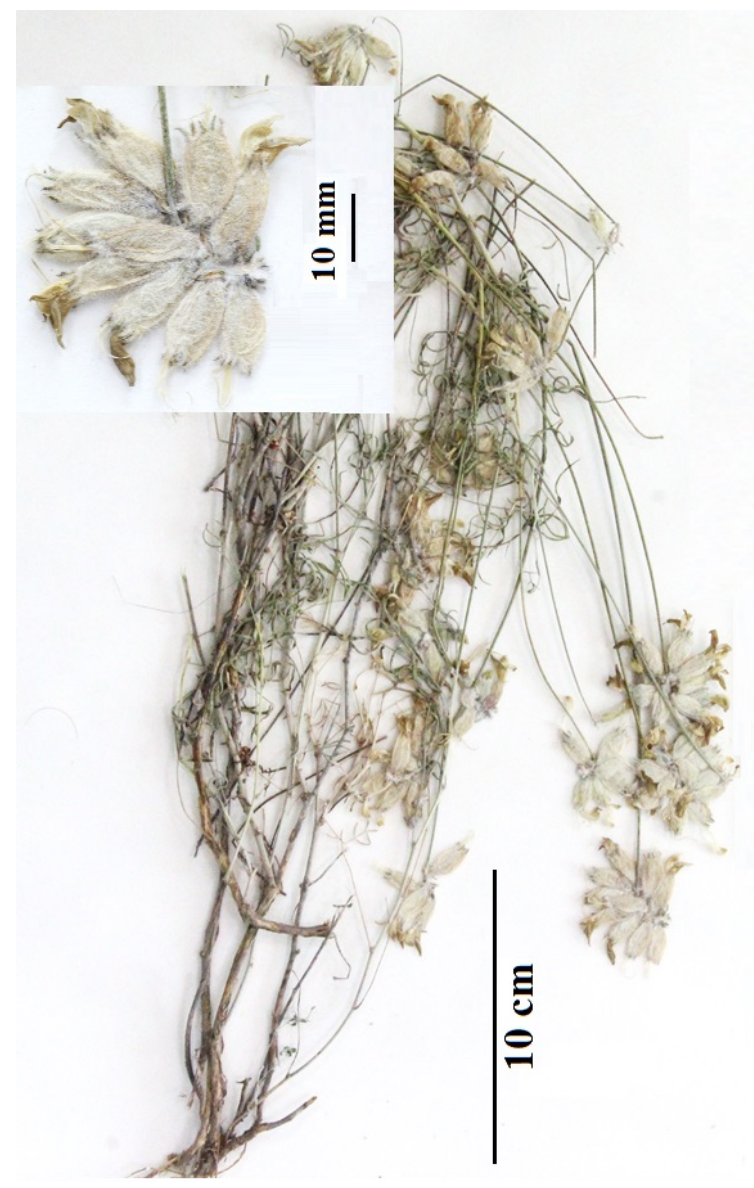

Şekil 21: Astragalus polemoniacus - Habit ve çiçekler.

Tablo 1: Yayılışı genişleyen taksonlar için öngörülen eski ve yeni IUCN tehdit kategorileri.

\begin{tabular}{lll}
\hline Takson & $\begin{array}{l}\text { Önceden } \\
\text { belirlenen IUCN } \\
\text { tehdit kategorisi }\end{array}$ & $\begin{array}{l}\text { Buada } \\
\text { belirlenen IUCN } \\
\text { tehdit kategorisi }\end{array}$ \\
\hline Achillea formosa subsp. amanica & $\mathrm{NT}$ & LC \\
Cirsium sivasicum & $\mathrm{EN}$ & $\mathrm{VU}$ \\
Doronicum macrophyllum subsp. sparsipilosum & $\mathrm{LC}$ & $\mathrm{LC}$ \\
Galatella linosyris subsp. linosyris & - & $\mathrm{NT}$ \\
Dianthus macroflorus & $\mathrm{EN}$ & $\mathrm{VU}$ \\
Gypsophila festucifolia & $\mathrm{VU}$ & $\mathrm{NT}$ \\
Delphinium cinereum & $\mathrm{VU}$ & $\mathrm{NT}$ \\
Ranunculus flammula var. ovalis & - & $\mathrm{EN}$ \\
Onosma nigricaulis & $\mathrm{VU}$ & $\mathrm{VU}$ \\
Sisymbrium malatyanum & $\mathrm{CR}$ & $\mathrm{EN}$ \\
Tuberaria guttata & - & $\mathrm{NT}$ \\
Convolvulus oleifolius var. deserti & - & $\mathrm{NT}$ \\
Cephalaria aytachii & $\mathrm{CR}$ & $\mathrm{VU}$ \\
Astragalus polemoniacus & $\mathrm{CR}$ & $\mathrm{NT}$ \\
\hline
\end{tabular}




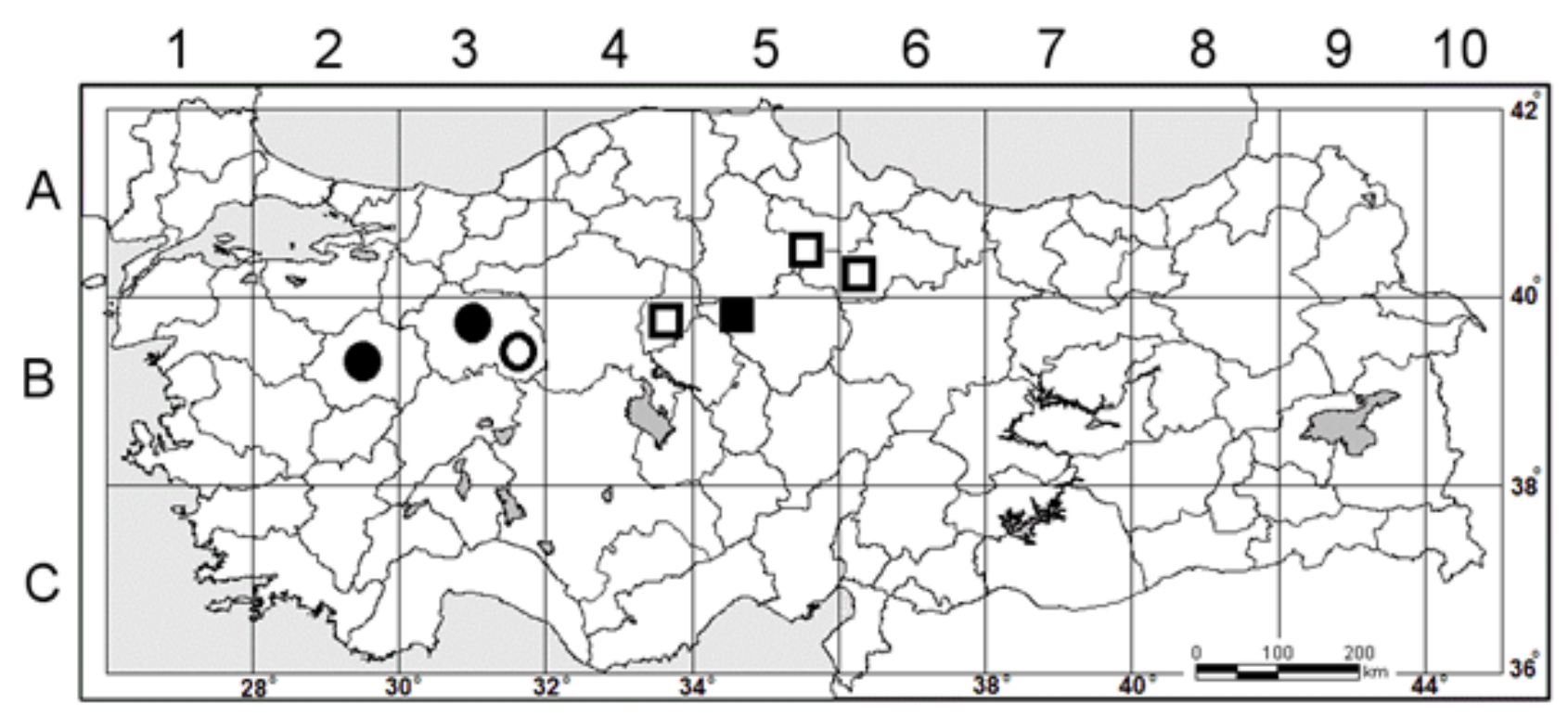

Şekil 20: Cephalaria aytachii'nin bilinen $(\mathbf{O})$ ve yeni tespit edilen $(\mathbf{O})$ popülasyonları.

\section{Kaynaklar}

Aykurt, C. \& Sümbül, H. 2010. Varieties and chorology of Convolvulus oleifolius Desr. (Convolvulaceae) in Turkey. Biological Diversity and Conservation 3(2): 155-162.

Chamberlain, D.F. \& Matthews, M.A. 1970. Astragalus L. In Flora of Turkey and the East Aegean Islands, Vol. 3. Ed. Davis, P.H. Edinburgh: Edinburgh University Press. 252-253 pp.

Davis, P.H. 1965a. Delphinium L. In Flora of Turkey and the East Aegean Islands, Vol. 1. Ed. Davis, P.H. Edinburgh: Edinburgh University Press. $119 p$.

Davis, P.H. 1965b. Ranunculus L. In Flora of Turkey and the East Aegean Islands, Vol. 1. Ed. Davis, P.H. Edinburgh: Edinburgh University Press. 191-192 pp.

Edmondson, J.R. 1975. Doronicum L. In: Flora of Turkey and the East Aegean Islands, Vol. 5. Ed. Davis, P.H. Edinburgh: Edinburgh University Press. 144-145 pp.

Ekim, T., Koyuncu, M., Vural, M., Duman, H., Aytaç, Z. \& Adıgüzel, N 2000. Türkiye Bitkileri Kırmızı Kitabı. TTKD ve Van 100. Yıl Üniversitesi Yayını, Ankara.

Göktürk, R.S. \& Sümbül, H. 2003. Cephalaria aytachii (Dipsacaceae), a new species from central Anatolia, Turkey. Annales Botanici Fennici 40: 123127.

Grierson, A.J.C. 1975a. Leucocyclus Boiss. In: Flora of Turkey and the East Aegean Islands, Vol. 5. Ed. Davis, P.H. Edinburgh: Edinburgh University Press. $224 p$.

Grierson, A.J.C. 1975b. Crinitaria Cass. In: Flora of Turkey and the East Aegean Islands, Vol. 5. Ed. Davis, P.H. Edinburgh: Edinburgh University Press. $123 p$.

Hamzaoğlu, E., Koç, M., Büyük, İ., Aksoy, A. \& Soydam Aydın, S. 2015. Presence of Dianthus roseoluteus Velen. (Caryophyllaceae) in Turkey and a new species: Dianthus macroflorus Hamzaoğlu. Systematic Botany 40(1): 208-213.

Hedge, I.C. 1965. Sisymbrium L. In Flora of Turkey and the East Aegean Islands, Vol. 1. Ed. Davis, P.H. Edinburgh: Edinburgh University Press. 481-485 pp.

Huber-Morath, A. 1967. Gypsophila L. In Flora of Turkey and the East Aegean Islands, Vol. 2. Ed. Davis, P.H. Edinburgh: Edinburgh University Press. $160 \mathrm{pp}$.

IUCN. 2001. IUCN Red List Categories and Criteria Version 3.1. Prepared by the IUCN Criteria Review Working Group. IUCN, Cambridge [http://www.iucnredlist.org, Erişim tarihi: 20.4.2018].

Karaer, F., Hamzaoğlu, E. \& Tunç, U. 2015. Yetersiz verili endemik Niksar Geveninin (Astragalus polemoniacus) bugünkü durumu. 1. Ulusal Bitki Biyolojisi Kongresi, 2-4 Eylül 2015, Bolu.
Küçükbay, F.Z., Kuyumcu, E., Günal, S. \& Arabac1, T. 2011. Composition and antimicrobial activity of the essential oil of Achillea formosa subsp. amanica. Chemistry of Natural Compounds 47(2): 300-302.

Mutlu, B. \& Karakuş, Ş. 2015. A new species of Sisymbrium (Brassicaceae) from Turkey: morphological and molecular evidence. Turkish Journal of Botany 39: 325-333.

Parris, B.S. 1978. Convolvulus L. In Flora of Turkey and the East Aegean Islands, Vol. 6. Ed. Davis, P.H. Edinburgh: Edinburgh University Press. 208-209 pp.

Prati, D. \& Peintinger, M. 2000. Biological flora of Central Europe: Ranunculus reptans L. Flora 195: 135-145.

Riedl, H. 1978. Onosma L. In Flora of Turkey and the East Aegean Islands, Vol. 6. Ed. Davis, P.H. Edinburgh: Edinburgh University Press. 348 p.

Tutin, T.G. \& Akeroyd, J.R. 1993. Ranunculus L. In Flora Europaea. Vol. 1. Lycopodiaceae to Platanaceae (Ed. 1). Eds. Tutin, T.G. et al. Cambridge: Cambridge University Press. 269-286 pp.

Whittemore, A. 1997. Ranunculus L. In Flora of North America Committee (Eds.), Flora of North America North of Mexico, vol. 3. Magnoliophyta: Magnoliidae and Hamamelidae. New York: Oxford University Press. 88135 pp. [http:// www.efloras.org, Erişim tarihi: 20.4.2018].

Yıldız, B., Arabacı, T., Dirmenci, T. \& Çelenk, S. 2011. Cirsium sivasicum sp. nov. and C. peshmenianum sp. nov. (Asteraceae) and their allies from Turkey. Nordic Journal of Botany 29: 26-37. 